\title{
Alüminyum Balpeteği Soğurucu Yüzeye Sahip bir Güneş Hava Kollektörünün HAD Analizi
}

\author{
Sharif Eyyublu ${ }^{1}$, Mahmut Sami Büker ${ }^{2 *}$ \\ 1* Necmettin Erbakan Üniversitesi, Enerji Sistemleri Mühendisliği Bölümü, Konya, Türkiye, (ORCID: 0000-0002-9700-5187), sharifeyyublu@ @gmail.com \\ ${ }^{2}$ Necmettin Erbakan Üniversitesi, Enerji ve Yarı iletkenler Araştırma Grubu, BITAM, Konya, Türkiye (ORCID: 0000-0002-0896-2293), msbuker@erbakan.edu.tr
}

(Uluslararası Araştırma-Geliştirme ve Tasarım Konferansı - 15-18 Aralık 2021)

(DOI: 10.31590/ejosat.1039534)

ATIF/REFERENCE: Eyyublu, S., BÜKER, M.S. (2021). Alüminyum Balpeteği Soğurucu Yüzeye Sahip bir Güneş Hava Kollektörünün HAD Analizi. Avrupa Bilim ve Teknoloji Dergisi, (32), 484-490.

\section{Öz}

Bu çalışmada, bir güneş hava kollektörü tasarımının hava çekiş yerine göre HAD (Hesaplamalı Akışkanlar Dinamiği) analizleri gerçekleştirilmiştir. Güneş hava kollektörünün verimini artırmak için balpeteği geometrisine sahip bir alüminyum soğurucu plaka kullanılmıştır. Isı transferi ve hava akış özelliklerini incelemek için merkez ve kenar hava çekişli güneş hava kollektörünün HAD analizleri yapılmış, farklı 1şınım ve kütle debileri altında sistemin optimum çalışma aralıkları belirlenerek merkez ve kenar hava çekişli kollektörlerin tasarım karşılaştırılması yapılmıştır. Alüminyum balpeteği yapılı kollektörlerin, $600-1000 \mathrm{~W} / \mathrm{m}^{2} 1$ 1şınım, 0.01 $0.015 \mathrm{~kg} / \mathrm{s}$ kütle debileri ve $300 \mathrm{~K}$ sabit hava giriş sıcaklığı için termal analizleri gerçekleştirilmiş ve çıkan hava sıcaklık artış değerleri ve karşılık gelen termal verimlilikler bulunmuştur. Bulgular, kenar çekişli ve merkez çekişli güneş hava kollektöründen en yüksek hava sıcaklık çıkışının, $1000 \mathrm{~W} / \mathrm{m}^{2}$ 1şınım ve $0.01 \mathrm{~kg} / \mathrm{s}$ kütlesel debide sırasıyla $312 \mathrm{~K}$ ve $310 \mathrm{~K}$ olduğunu göstermiştir. En yüksek termal verimlilikler ise benzer şekilde her iki konfigürasyon için $600 \mathrm{~W} / \mathrm{m}^{2} 1$ şınım ve $0,015 \mathrm{~kg} / \mathrm{s}$ debide, kenar çekişli kollektör için yaklaşık \%45, merkez çekişli kollektör için ise $\% 42$ olarak gerçekleşmiştir.

Anahtar Kelimeler: Güneş hava kollektörü, HAD (Hesaplamalı Akışkanlar Dinamiği) analizi, Balpeteği soğurucu plaka.

\section{CFD Analysis of a Solar Air Collector with Aluminum Honeycomb Absorber Plate}

\begin{abstract}
In this study, CFD (Computational Fluid Dynamics) analyses of two different solar air collector configurations according to the air intake spot were performed. An aluminum absorber plate with honeycomb geometry is used to increase the efficiency of the solar air collector. In order to examine the heat transfer and air flow properties, simulation analyses were carried out on the solar air collector with air-draught from the center and side. The optimum operating ranges of the system under different radiation and mass flow rates were determined and the design comparison of the center and side aspirated collectors was performed. Thermal analysis of collectors with aluminum honeycomb absorber plate were carried out for $600-1000 \mathrm{~W} / \mathrm{m}^{2}$ radiation, $0.01-0.015 \mathrm{~kg} / \mathrm{s} \mathrm{mass}$ flow rates and constant $300 \mathrm{~K}$ inlet air temperature. Temperature rise in outlet air and corresponding thermal efficiencies were found. The findings show that the highest temperature output is approximately 312 and $310 \mathrm{~K}$ at $1000 \mathrm{~W} / \mathrm{m}^{2}$ irradiance and $0.01 \mathrm{~kg} / \mathrm{s}$ mass flow rate for edge and center air draught type solar air collectors, respectively. The highest thermal efficiencies, on the other hand, were approximately $45 \%$ for the side air intake collector and $42 \%$ for the center air intake collector both at $600 \mathrm{~W} / \mathrm{m}^{2} \mathrm{irradiance}$ and 0.015 $\mathrm{kg} / \mathrm{s}$ flow rate for both configurations,.
\end{abstract}

Keywords: Solar air collector, CFD (Computational Fluid Dynamics) analysis, Honeycomb absorber plate.

\footnotetext{
*Sorumlu Yazar: msbuker@erbakan.edu.tr, msbuker@gmail.com
} 


\section{Giriş}

Güneş hava kollektörleri, basit tasarımı, düşük imalat ve işletme maliyeti nedeniyle güneş enerjisinden faydalanmak için yaygın olarak kullanılan sistemlerdir. Güneş hava kollektörü, güneş 1şınımını toplayan ve 1sıyı havaya aktaran bir 1S1 eşanjörüdür. Isıtılmış hava, mahsul kurutma, çamaşır kurutma ve alan 1sıtma gibi çeşitli uygulamalarda kullanılır [1]. En yaygın kullanılan güneş hava kollektörü tipi, düz plakalı hava kollektörüdür. $\mathrm{Bu}$ tip kollektörler hem doğrudan hem de yayılmış (difüze) güneş ışınımını emebilir ve 1sıyı, alan ısıtma amacıyla dış ortamdan iç ortama iletebilir [2].

Bununla birlikte, havanın düşük 1S1 transfer katsayısı nedeniyle, 1sı toplama verimlilikleri oldukça düşüktür. Hava, suya veya güneş enerjisi sistemlerinin diğer çalışma sıvılarına göre nispeten daha küçük bir yoğunluğa ve daha düşük 1s1 transfer katsayısına sahiptir, bu da daha büyük 1sı kayıplarına ve dolayısıyla sıvı kollektörlere kıyasla düz plakalı hava kollektöründe daha düşük bir termal verimliliğe neden olur [3]. Özellikle doğal sirkülasyonlu güneş hava kollektörlerinde, yavaş hava sirkülasyon hızı, hava ile soğurucu plaka arasında daha düşük 1sı transfer hızına neden olur. İçeriye yeterli miktarda 1s1 sağlamak için ya hava akış hızı ya da 1Sı toplama kabiliyeti arttırılmalıdır [4].

$\mathrm{Bu}$ faktörler, geleneksel güneş hava kollektörlerinin yaygın kullanımını büyük oranda kısıtlamaktadır. Dolayısıyla, güneş hava kollektörü uygulamalarında 1 sı transferini artırmak için çeşitli teknikler uygulanmıştır. Çalışmalarda, soğurucu plaka ve hava akışı arasındaki 1sı transfer katsayısını iyileştirmek amacıyla güneş hava kollektörlerinin soğurucu levhalarının tasarımında çeşitli konfigürasyonlar önerilmiştir [5]. Bu tasarımların prensibi, plakanın temas alanını olabildiğince genişletmek ve plakanın etrafında türbülans oluşturarak 1s1 transfer katsayısını büyütmek, böylece plaka tarafından emilen ve havaya aktarılan 1sı miktarını arttırmaktır [6].

Literatürdeki bazı çalışmalara bakıldığında, basit kanatçıklar [7], V-oluklu [8], dört geçişli [9], çapraz oluklu [10] gibi yöntemlerle soğurucu plaka alanlarında artış elde edilmiştir. Priyam ve Chand [11] dalgalı kanatlı bir güneş hava kollektörünün termal performansı üzerindeki kütle akış hızı, genişlik ve dalga boyu varyasyonunun etkisini analiz etmiştir. Sonuçlar, sıradan hava kollektörleri ile karşılaştırıldığında, modifiye oluklu kanatlı yapıdaki kollektörün daha yüksek termal verimliliğe ve etkili sıcaklık artışına sahip olduğunu göstermiştir. En büyük verim artışı, genişlik en yüksek ve dalga boyu en küçük olduğunda \%17,56 olarak bulunmuştur. Jing ve ark. [12] 1şınım ve PV panel kaplama oranının, alüminyum balpeteği soğuruculu güneş hava kollektörünün genel termal verimliliği üzerindeki etkisini deneysel olarak araştırmıştır. Sistem, \%15, $\% 30, \% 45, \% 60, \% 75$ ve $\% 90$ PV kaplama oranı ile $200 \mathrm{~W} / \mathrm{m}^{2}$ ila $600 \mathrm{~W} / \mathrm{m}^{2}$ 1şınım altında deneysel olarak test edilmiş ve sistemin termal davranışı analiz edilmiştir. Deneysel koşullar aralığında, PV kapsama oranı \%45 olduğunda maksimum anlık verimliliğin \%64'e ulaştığı tespit edilmiştir. Alüminyum balpeteği ayrıca, gizli termal enerji depolama ve dolayısıyla termal verimliliği artırmak için faz değiştiren malzemelerle (PCM'ler) birleştirilerek, güneş hava kollektöründe kullanılmıştır [13]. Zülkifle ve ark. [14] deneysel çalışmalarında V-oluğunun konvektif ısı transferini artırdığını ve daha iyi termal verim elde edildiğini, elde edilen en yüksek sıcaklığın $38.39^{\circ} \mathrm{C}$ olduğunu belirtmiştir. Fudholi ve ark. [15], PV/T SAC ile donatılmış v- oluklu bir soğurucuyu deneysel ve teorik olarak değerlendirmiştir. Ekserji verimi deneylerde \%13,36, teorik analizlerde \%12,89 olarak bulunmuştur. Kerem ve ark. [16], çok geçişli hava akışı oluşturmak için emici plaka üzerine gözenekli malzemeler eklemişlerdir. $\mathrm{Bu}$ çalışmada, güneş hava kollektörünün performanslarının belirgin bir şekilde iyileştiğini uyumlu bir şekilde göstermiştir. Kollektör soğurucu bölmesine delikli ve deliksiz bölmeler eklemek, hava akışı düzenini değiştirmek için başka bir uygulamadır.

$\mathrm{Bu}$ çalışmada, güneş hava kollektörlerinin düşük verimlilik sorununu çözmeyi amaçlayan yeni bir soğurucu katman türü olarak alüminyum balpeteği önerilmiş, hava giriş yerinin kollektör performansına olan etkisini belirlemek için HAD analizi yapılmıştır. Alüminyum balpeteği dikey olarak metalik (alüminyum) petek plakanın merkeze, hava kanalının bir parçası ve soğurucu katman olarak yerleştirilmesi önerilmiştir. Literatürde çalışmaları yapılmış yapay pürüzlülük, hava akış bölmeleri veya çoklu geçişler oluşturmak gibi bilinen teknikler yerine, önerilen soğurucu katmanın petek delikleri sadece yüzey alanını büyütüp daha fazla termal enerji emmekle kalmaz, aynı zamanda türbülans oluşturur ve havanın kollektörde kalma süresini uzatır. Bu da 1sı transfer miktarını daha da artıracaktır. Ayrıca, bir elektrikli fan da, iç hava akışının doğal konveksiyonu yerine zorlanmış taşınım sağlamak ve termal verimliliği daha da artırmak için kollektör sistemine eklenmiştir.

Kollektörün tasarım optimizasyonu, sistemin farklı konfigürasyonlarını karşılaştırmayı ve en uygun çözümü bulmayı gerektirir. $\mathrm{Bu}$ nedenle araştırmanın temel amacı, kollektörün hava giriş yerlerine göre termal performansının HAD analizi aracılığıyla araştırılmasıdır. HAD analizi, çeşitli radyasyon seviyeleri altında farklı debiler için ve farklı hava giriş yerlerine göre gerçekleştirilmiştir. Analiz sonuçları karşılaştırmış, hava giriş yerinin, farklı 1şınım ve debiler için kollektörün termal özellikleri üzerindeki etkisi incelenmiştir.

\section{Materyal ve Metot}

\subsection{Akış Koşulları, Türbülans ve Radyasyon Modelinin Seçilmesi}

$\mathrm{Bu}$ çalışmada, iç geometrisi altıgen balpeteği olan güneş hava kollektörünün hava akışının hesaplamalı akışkanlar dinamiği (HAD) simülasyonu ile analizleri gerçekleştirilmiştir. Alüminyum balpetekli soğurucu yüzeye sahip hava kollektörünün simülasyon çalışması, kütle akış hızı, güneş radyasyonu ve giriş hava sıcaklığı değiştirilerek, farklı giriş koşulları altında gerçekleştirilmiştir. HAD simülasyonunun doğruluğunun belirlenmesi için birçok araştırmacı tarafından doğrulanmış türbülans metotları kullanılmıştır [17], [18], [19]. Çalışmanın nihai amacı analizi yapılacak güneş hava kollektörünün 1S1 transferi performansını ve termal enerji kullanımını en üst seviyelere çıkaracak tasarım geliştirmek, farklı hava akış hızları altında kollektörün genel termal verimliliğini artırmak ve en yüksek verim elde etmek için optimum radyasyon ve hava akış hız değerlerini bulmaktır. $\mathrm{Bu}$ amaçla alüminyum balpeteği geometrisinin $(700$ x $515 \mathrm{~mm})$ termal özelliklerinin simülasyona dayalı analizleri gerçekleştirilmiştir. Farklı akış koşulları altında gerçekleştirilmiş hesaplamalı çalışmanın sonuçlarının gerçekliğini onaylamak, akışın geometri parametrelerinin termal performansı üzerindeki etkisini analiz etmek için uygun bir türbülans modeli seçilmelidir. Tasarım çalışmaları yapılmış, 
merkezi ve kenar hava çekişli kollektörlün 3 boyutlu sıvı akış analizi için, SST k- $\omega$ ve Realizable k- $\omega$ türbülans çözücü model olarak seçilmiştir [19].

Modelleme sürecinin önemli aşaması uygun bir radyasyon modeli uygulamaktır. Analiz çalışmasında radyasyon yoğunluğunu hesaplamak, akış ve 1sı transferinin çeşitlerini birleştirmek için DO (Discrete Ordinates) radyasyon modeli ve Güneş Işını Takip (Solar Ray Tracing) alt modeli kullanılmıştır [20].

\section{Yönetim Denklemleri}

Bir HAD analizinde 1sı transferi, hava akışı, enerji ve kütle denklemleri ile nihai bir sonuca ulaşılır. Bunun yanı sıra analiz sonuçları başlangıç ve sınır koşullarına bağlıdır. Bu çalışmada yapılan analizler sonlu hacimler yöntemi kullanılarak ANSYS Fluent 2020 R2 yazılımı üzerinden yapılmıştır.

Süreklilik denklemi genellikle yük, kütle, enerji ve momentumun korunmasını tanımlar ve şu şekilde yazılır [21]:

$$
\frac{\partial P}{\partial t}+\nabla \cdot(\rho \vec{v})
$$

Kütle korunum denklemi şu şekildedir [21]:

$$
\frac{\partial \rho_{f} u}{\partial x}+\frac{\partial \rho_{f} u}{\partial y}+\frac{\partial \rho_{f} u}{\partial z}=0
$$

Momentum korunumu ise [21]:

$$
\begin{gathered}
u \frac{\partial \rho_{f} u}{\partial x}+v \frac{\partial \rho_{f} u}{\partial y}+\omega \frac{\partial \rho_{f} u}{\partial z}=-\frac{\partial p}{\partial z}+\mu\left(\frac{\partial^{2} u}{\partial x^{2}}+\frac{\partial^{2} u}{\partial y^{2}}+\frac{\partial^{2} u}{\partial z^{2}}\right) \\
u \frac{\partial \rho_{f} v}{\partial x}+v \frac{\partial \rho_{f} v}{\partial y}+\omega \frac{\partial \rho_{f} v}{\partial z}=-\frac{\partial p}{\partial z}+\mu\left(\frac{\partial^{2} v}{\partial x^{2}}+\frac{\partial^{2} v}{\partial y^{2}}+\frac{\partial^{2} v}{\partial z^{2}}\right) \\
u \frac{\partial \rho_{f} \omega}{\partial x}+v \frac{\partial \rho_{f} \omega}{\partial y}+\omega \frac{\partial \rho_{f} \omega}{\partial z}=-\frac{\partial p}{\partial z}+\mu\left(\frac{\partial^{2} u}{\partial x^{2}}+\frac{\partial^{2} u}{\partial y^{2}}+\frac{\partial^{2} u}{\partial z^{2}}\right)+ \\
\rho_{f} g
\end{gathered}
$$

Enerji denklemi aşagidaki gibidir [21]:

$$
\frac{\partial}{\partial t}(\rho E)+\nabla \cdot(\rho E+p) \bar{v}=\nabla \cdot k_{e f f} \nabla T+S_{h}
$$

Akışkan bölgesi için enerji korunumu ise [21]:

$$
\begin{gathered}
u \frac{\partial \rho_{f} c_{p f} T_{f}}{\partial x}+v \frac{\partial \rho_{f} c_{p f} T_{f}}{\partial y}+\omega \frac{\partial \rho_{f} c_{p f} T_{f}}{\partial z}=\lambda_{f}\left(\frac{\partial^{2} T_{f}}{\partial x^{2}}+\frac{\partial^{2} T_{f}}{\partial y^{2}}+\right. \\
\left.\frac{\partial^{2} T_{f}}{\partial z^{2}}\right)-\nabla \cdot q_{\text {rad }}
\end{gathered}
$$
[21]:

SST k- $\omega$ modeli için taşınım denklemi şöyle ifade edilir

$$
\begin{gathered}
\frac{\partial}{\partial t}(\rho k)+\frac{\partial}{\partial x_{j}}\left(\rho k u_{j}\right)=\frac{\partial}{\partial x_{j}}\left[\left(\mu+\frac{\mu_{t}}{\sigma_{t}}\right) \frac{\partial k}{\partial x_{j}}\right]+G_{k}+G_{b}- \\
\rho \varepsilon-Y_{M}+S_{k} \\
\frac{\partial}{\partial t}(\rho \varepsilon)+\frac{\partial}{\partial x_{j}}\left(\rho \varepsilon u_{j}\right)=\frac{\partial}{\partial x_{j}}\left[\left(\mu+\frac{\mu_{t}}{\sigma_{t}}\right) \frac{\partial k}{\partial x_{j}}\right]+\rho C_{1} S_{\varepsilon}- \\
\rho C_{2} \frac{\varepsilon^{2}}{k+\sqrt{v \varepsilon}}+C_{1 \varepsilon} \frac{\varepsilon}{k} C_{3 \varepsilon} G_{b}+S_{\varepsilon} \\
C_{1}=\max \left[0.43, \frac{\eta}{\eta+5}\right], \rightarrow \eta=S \frac{k}{\varepsilon}, \rightarrow S=\sqrt{2 S_{i j} S_{i j}} \\
\left(C_{1 \varepsilon}=1.44\right),\left(C_{2}=1.9\right),\left(\sigma_{k}=1.0\right),\left(\sigma_{\varepsilon}=1.2\right)
\end{gathered}
$$

Radyasyon transfer denklemi ise [21]:

$$
\begin{aligned}
& \nabla \cdot\left(I_{(\overrightarrow{r, s})} \vec{S}\right)=-\left(a_{f}+\sigma_{s c a}\right) I_{(\overrightarrow{r, s})}+a_{f} n^{2} \frac{\sigma T_{f}^{4}}{\pi}+ \\
& \quad \frac{\sigma_{s c a}}{4 \pi} \int_{4 \pi} I_{(\overrightarrow{r, \vec{s}})} \Phi_{(\overrightarrow{s, \vec{s}})} d \Omega
\end{aligned}
$$

$\mathrm{Bu}$ denklemler ANSYS Fluent 2020R2 yazılımı ile çözülmüştür.

\subsection{Hesaplamalı Akışkanlar Dinamiği Modeli}

Bu çalışmada, hava fanının konumuna göre çeşitlendirilmiş 2 tip güneş hava kollektörü tasarlanmıştır. Çalışmada kullanılan tasarımların kesitsel görünümleri Şekil 1'de gösterilmiştir. Analizleri gerçekleştirilen tasarımların ölçüleri, yapılan araştırmalar sonucunda $(515 \times 700 \times 55 \mathrm{~mm})$ belirlenerek havayı alt taraftan delikli plaka yardımıyla çekecek şekilde tasarlanmıştır. [22]. Kollektörlerin absorber yüzeyini $10 \mathrm{~mm}$ yükseklik ve $6 \mathrm{~mm}$ petek genişliğinde alüminyum balpeteği oluşturmaktadır (Şekil 2). Alüminyum balpeteği yapısı 1S1 transfer yüzeyinin artırılması için kullanılmıştır. Kollektörün üst tarafında düşük demirli temperli cam bulunmaktadır. Analiz sürecinde kollektörün kenarlarındaki 1sı kayıpları dikkate alınmamıştır. Alüminyum balpeteği, temperli cam, giriş ve çıkış kısımları sayısal analizi yapılmış kollektörün çözüme etki eden kisimlaridir.

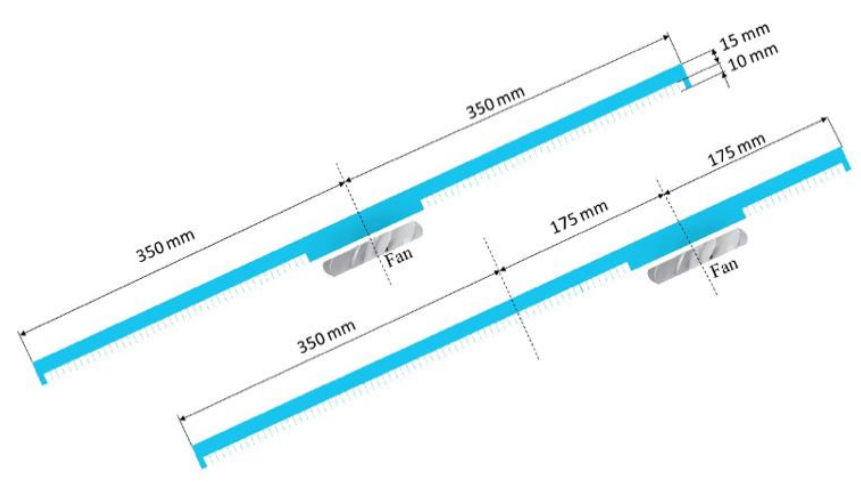

Şekil 1. Güneş hava kollektörünün yan kesit görünümü

Analizi yapılacak tasarımlar çözüm ağı modellemesi ANSYS Meshleme aracı yardımıyla oluşturulmuştur. Kollektörün üst yüzeyi, güneş 1şınlanmasının etki alanına girdiği yarı saydam bir sınır duvarıdır. Alüminyum balpeteği ise ona ulaşan ışınımın enerjisini absorbe ederek havaya aktaran etki alanı olarak belirlenmiştir. Analiz süresinin kısaltılması amacı ile alüminyum balpeteğinin sadece dış yüzeyleri çözüme dahil edilmiştir.

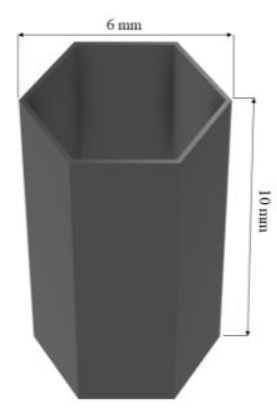

Şekil 2. Alüminyum balpeteği hücre ölçüleri

Tablo 1. Malzeme özellikleri

\begin{tabular}{l|c|c|c}
\hline & $\begin{array}{c}\text { Yoğunluk } \\
\mathrm{kg} / \mathrm{m}^{2}\end{array}$ & $\begin{array}{c}\text { Özgül 1s1 } \\
\mathrm{J} / \mathrm{kg} \cdot \mathrm{K}\end{array}$ & $\begin{array}{c}\text { Termal iletkenlik } \\
\mathrm{W} / \mathrm{m} \cdot \mathrm{K}\end{array}$ \\
\hline Alüminyum & 2719 & 871 & 202.4 \\
\hline Cam & 2530 & 210 & 0,937 \\
\hline Hava & 1.225 & 1006 & 0.0242 \\
\hline \multicolumn{4}{|c}{486}
\end{tabular}




\subsubsection{Başlangıç ve Sınır Koşulları}

$\mathrm{Bu}$ çalışmada kabul edilmiş sınır koşulları, analizi kolaylaştırmak ve analiz süresini kısaltmayı amaçlamaktadır. Analiz süresi boyunca kabul edilmiş sınır koşulları bu kısımda belirtilecektir.

Analiz süreci boyunca kullanılan kabul ve sınır koşulları aşağıdaki gibidir:

- Hava akışı 3B kabul edilmiştir,

- Giriş sıcaklığı sabittir (300K),

- Yan duvarlarda 1sı kayıpları tamamen izole edilmiştir,

- Türbülans viskozite oranı \%10 kabul edilmiştir,

- Türbülans kayıp oranı \%5 kabul edilmiştir,

- Analiz süresi sabit durum olarak kabul edilmiştir,

- Giriş ve çıkışlar kütle olarak tanımlanmıştır.

\section{Araştırma Sonuçları ve Tartışma}

Alüminyum balpeteği soğurucu yüzeye sahip güneş hava kollektörünün 2 farklı tasarımı için sıcaklık artışına bağlı olarak termal verimlilik ve soğurucu yüzeyin sıcaklık değişim sonuçları bu kısımda açıklanacaktır. Analizleri gerçekleştirilen tasarım 1'de hava çekiş fanı peteğin kenar kısmında, tasarım 2'de ise merkezde konumlandırılmıştır. Tasarım 1 için sıcaklık dağılımı Bölüm 3.1'de, tasarım 2 için ise sıcaklık dağılımı Bölüm 3.2'de sunulmuş ve değerlendirilmiştir.

\subsection{Tasarım 1 için sıcaklık dağılımı}

Güneş hava kollektörünün kenar kısmından hava çıkışı olan tasarım 1 için 4 farklı analiz gerçekleştirilmiştir. İki farklı ışınım $\left(600 \mathrm{~W} / \mathrm{m}^{2}, 1000 \mathrm{~W} / \mathrm{m}^{2}\right)$ ve iki farklı debi $(0.001 \mathrm{~kg} / \mathrm{s}, 0.015 \mathrm{~kg} / \mathrm{s})$ için gerçekleştirilen dört analiz sonucunda ulaşılan güneş hava kolektörünün sicaklık dağılımları aşağıda gösterilmiştir.

Şekil 3 incelendiğinde, güneş hava kollektörünün köşe bölgelerinde hava sicaklığının daha yüksek olduğu görülmektedir. Soğurucu yüzeyin kenarlarındaki sıcaklık $338 \mathrm{~K}$ olurken, hava çıkış sıcaklığı $312 \mathrm{~K}$ olduğu gözlenmiştir. Bunun esas sebebi o bölgelerin fanın çekim alanından uzak mesafede olması, hava akışının daha yavaş olması ve fan tarafindan etkin şekilde çekilememesidir. Şekil 4'deki analiz sonuçları incelendiğinde hava debisinin yüksek olması sonucunda soğurucu yüzeyin fandan uzak olan orta kısımlarında hava yüzey sıcaklığını tam olarak soğurmamıştır. Şekil 5 için soğurucu yüzey sıcaklığı köşe kısımlardan fana doğru azalmıştır. Bunun sebebi diğer analiz sonuçlarındaki gibi o kısımların fanın çekim alanından uzak kalmasıdır. Şekil 6 için analiz sonuçlarına bakıldığında ise diğer analiz sonuçları ile neredeyse aynı performans gösterdiği görülmüştür. Kenar kısımlardan fana doğru yüzey sıcaklığındaki düşüş, fanın çekim alanı kapsamındaki havanın 1sıyı daha iyi soğurulduğu sonucu çıkarılabilir.

\subsection{Termal verimliliğin hesaplanması}

Güneş hava kollektöründeki faydalı enerji havanın giriş $\left(\mathrm{T}_{\mathrm{i}}\right)$ ve çıkış $\left(\mathrm{T}_{\mathrm{o}}\right)$ sıcaklıklarına bağlı olarak değişir [23].

$$
Q_{u}=\dot{m} c_{p}\left(T_{o}-T_{i}\right)
$$

Burada, m kollektörden geçen havanın kütle akış hızı $(\mathrm{kg} / \mathrm{s})$, $\mathrm{c}_{\mathrm{p}}$ ise havanın özgül ısısıdır $(\mathrm{J} / \mathrm{kgK})$

Termodinamiğin birinci yasasına bağlı olarak, güneş hava kollektörünün termal verimliliği aşağıdaki denklem ile hesaplanır [23]:

$$
\eta_{\text {termal }}=\frac{\dot{m} c_{p}\left(T_{0}-T_{i}\right)}{I A_{s}}
$$

Burada, I toplayıcı yüzeye gelen güneş radyasyonu $\left(\mathrm{W} / \mathrm{m}^{2}\right)$, $A_{s}$ ise kollektörün üst şeffaf yüzey alanıdır $\left(\mathrm{m}^{2}\right)$.
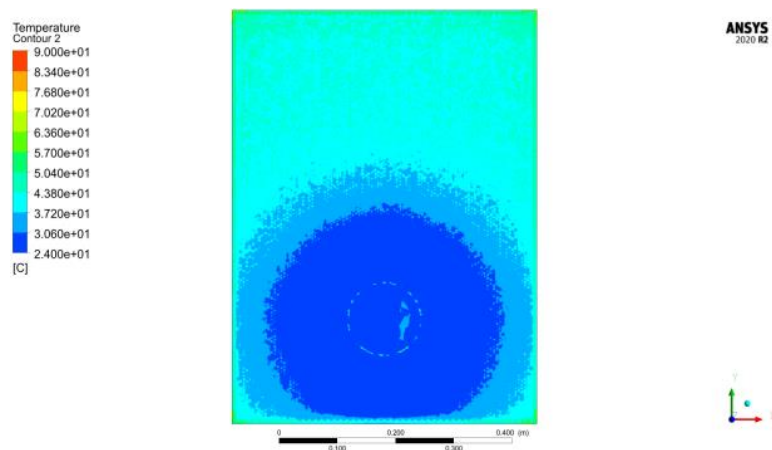

Şekil 3. Kenar hava çekişli güneş hava kollektöründe soğurucu yüzeyin sıcaklık değişimi $\left(1000 \mathrm{~W} / \mathrm{m}^{2} 1\right.$ şınım ve $0.01 \mathrm{~kg} / \mathrm{s} \mathrm{debi)}$
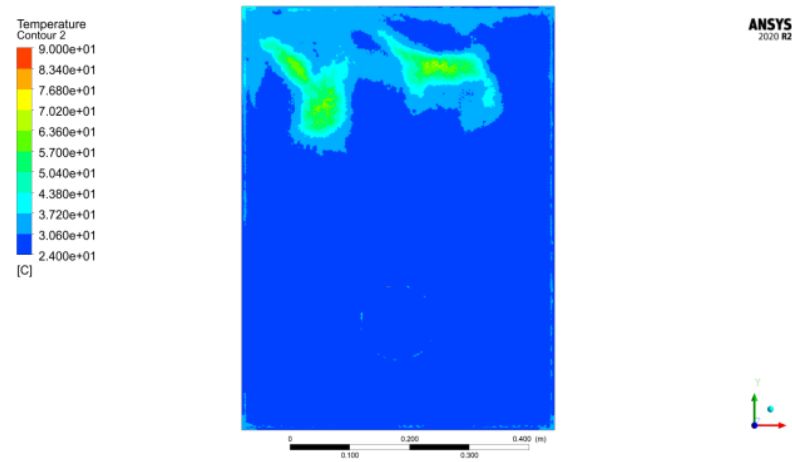

Şekil 4. Kenar hava çekişli güneş hava kollektöründe soğurucu yüzeyin sıcaklık değişimi $\left(600 \mathrm{~W} / \mathrm{m}^{2}\right.$ 1şınım ve $0.01 \mathrm{~kg} / \mathrm{s} \mathrm{debi)}$

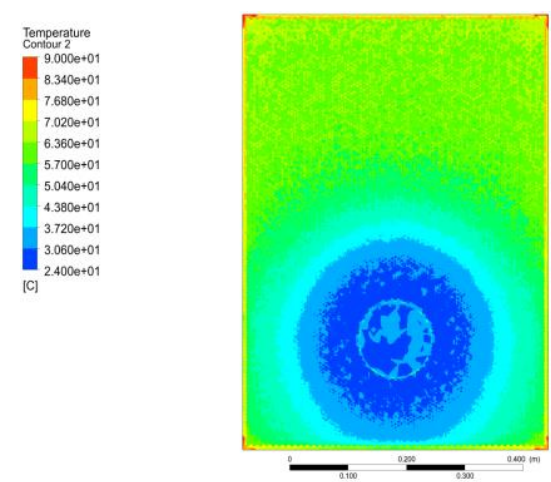

ANSYS

Şekil 5. Kenar hava çekişli güneş hava kollektöründe soğurucu yüzeyin sıcaklık değişimi $\left(1000 \mathrm{~W} / \mathrm{m}^{2} 1\right.$ şınım ve $0.015 \mathrm{~kg} / \mathrm{s}$ debi) 

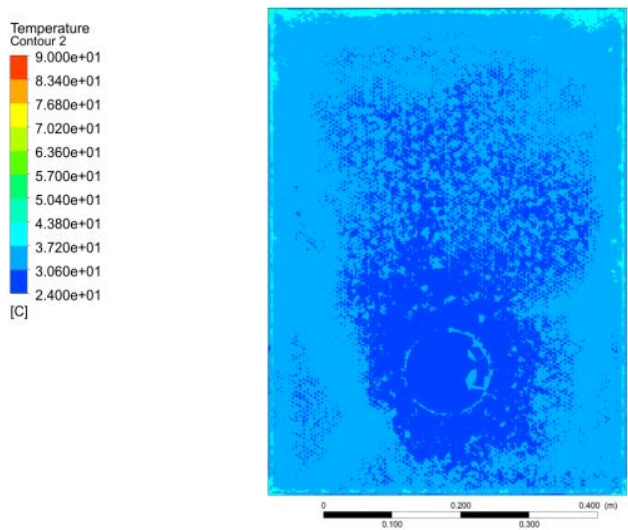

Şekil 6. Kenar hava çekişli güneş hava kollektöründe soğurucu yüzeyin sıcaklık değişimi $\left(600 \mathrm{~W} / \mathrm{m}^{2} 1\right.$ şınım ve $0.015 \mathrm{~kg} / \mathrm{s}$ debi)

Elde edilen bulgular güneş hava kollektöründen en yüksek sıcaklık çıkışına, $1000 \mathrm{~W} / \mathrm{m}^{2} 1$ şınım ve $0.01 \mathrm{~kg} / \mathrm{s}$ kütle debisi için gerçekleştirilen analizde ulaşıldı̆̆ını göstermektedir (Şekil 7). Ancak termal verimlilik hesaplamaları sonucunda en düşük termal verimliliğin yine $1000 \mathrm{~W} / \mathrm{m}^{2} 1$ şınım ve $0.01 \mathrm{~kg} / \mathrm{s}$ kütle debisi için yapılan analizde olduğu görülürken, en yüksek termal verimliliğin ise $600 \mathrm{~W} / \mathrm{m}^{2} 1$ şınım, $0,015 \mathrm{~kg} / \mathrm{s}$ debi için gerçekleştirilen teste ait olduğu görülmektedir (Şekil 8).

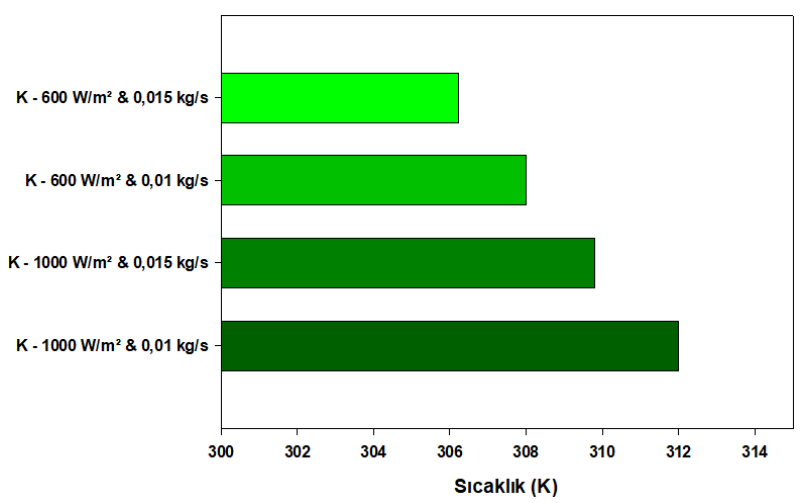

Şekil 7. Kenar hava çekişli güneş hava kollektöründe çıkış sıcaklığ 1 değişimi

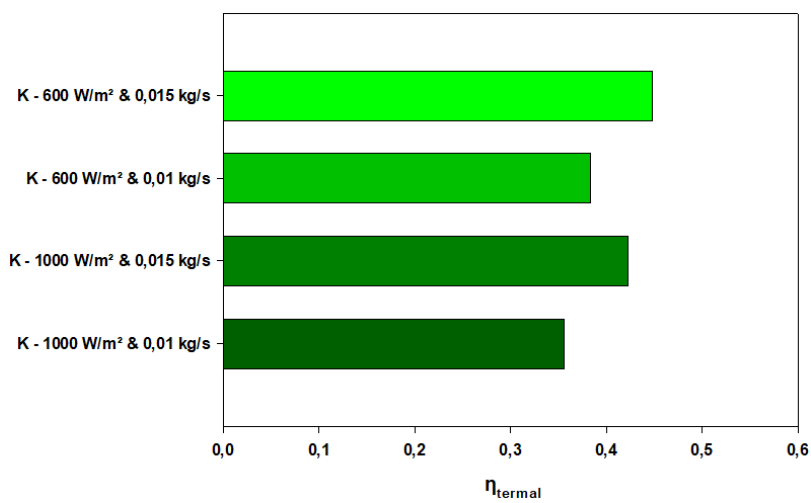

Şekil 8.Kenar hava çekişli güneş hava kollektöründe termal verimlilik değişimi

\subsection{Tasarım 2 için sıcaklık dağılımı}

Güneş hava kollektörünün merkez kısmından hava çıkışı olan tasarım 2 için ise, farklı 1şınım $\left(600 \mathrm{~W} / \mathrm{m}^{2}, 1000 \mathrm{~W} / \mathrm{m}^{2}\right)$ ve farklı debiler $(0.001 \mathrm{~kg} / \mathrm{s}, 0.015 \mathrm{~kg} / \mathrm{s})$ için 4 farklı analiz ans gerçekleştirilmiş ve bu analizlere ait güneş hava kollektörünün sıcaklık dağılımları aşağıda gösterilmiştir.

Şekil 9 incelendiğinde özellikle $1000 \mathrm{~W} / \mathrm{m}^{2}$ 1şınım, 0,01 $\mathrm{kg} / \mathrm{s}$ debi ve $600 \mathrm{~W} / \mathrm{m}^{2} 1$ şınım, $0,015 \mathrm{~kg} / \mathrm{s}$ debi için yapılan analizlerde, kollektörün köşeleri ile fan çevresi arasındaki sıcaklık farkının oldukça yüksek olduğu dikkat çekmektedir. Merkez çekişli kollektörde köşelerdeki havanın neredeyse çıkışa ulaşamadığı yorumu yapılabilir. Şekil 10'daki analiz sonuçları incelendiğinde diğer merkezi fan çekişli kollektörlerle aynı performans değerleri gösterdiği görülmüştür. Fakat $600 \mathrm{~W} / \mathrm{m}^{2}$ altında soğurucu yüzeyin kenar kısımlarında sıcaklık değerinin

¿- $358 \mathrm{~K}$ olduğu görülmüştür. Bunun sonucunda çıkış sıcaklığ 308 K'e ulaşmıştır. Şekil 11 için yapılan analiz sonuçlarında ise 1000 $\mathrm{W} / \mathrm{m}^{2}$ 1şınım değeri altında kollektörün soğurucu yüzeyinin kenar kısımlarından merkeze doğru büyük bir kısmında sıcaklık değeri 360 K'e ulaşmıştır. Sonuç olarak fanın kapsama alanında çekilen havanın fana yakın yüzeylerde 1sıyı daha iyi soğurduğu görülmüştür. Sonuç olarak çıkış sıcaklığı 309K'e ulaşmıştır. Şekil 2'deki analiz sonuçlarından görüldüğü gibi $600 \mathrm{~W} / \mathrm{m}^{2}$ ışınım değeri altında soğurucu yüzeyin kenar kısımlarındaki ısı tam olarak soğrulamamıştır. Kenar kısımlarda soğurucu yüzeyin en yüksek sıcaklık değeri 338K iken çıkış sıcaklığının 306K olduğu görülmüştür.

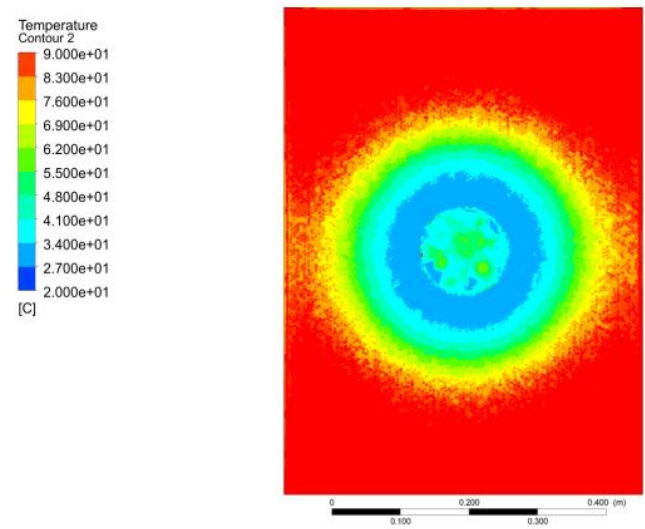

$\underset{2020 \text { ค2 }}{\text { ANSYS }}$

Şekil 9. Merkez hava çekişli güneş hava kollektöründe soğurucu yüzeyin sıcaklık değişismi $\left(1000 \mathrm{~W} / \mathrm{m}^{2} 1\right.$ şınım ve $0.01 \mathrm{~kg} / \mathrm{s}$ debi)
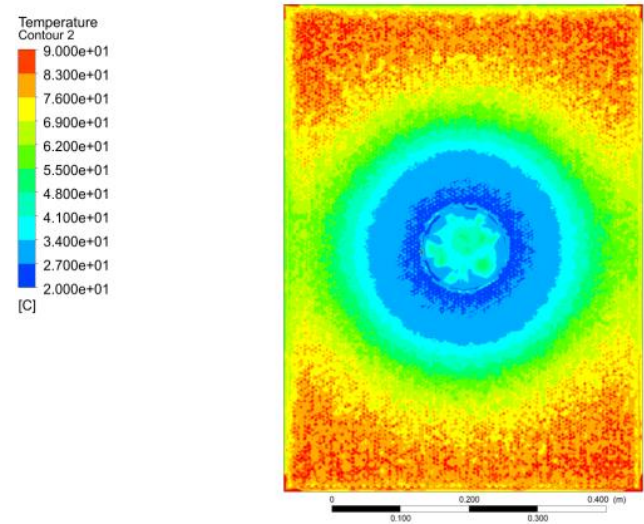

$\underset{2020 \mathrm{R2}}{\text { ANSYS }}$

Şekil 10. Merkez hava çekişli güneş hava kollektöründe soğurucu yüzeyin sıcaklık değişimi $\left(600 \mathrm{~W} / \mathrm{m}^{2}\right.$ 1şınım ve 0.01 $\mathrm{kg} / \mathrm{s}$ debi) 

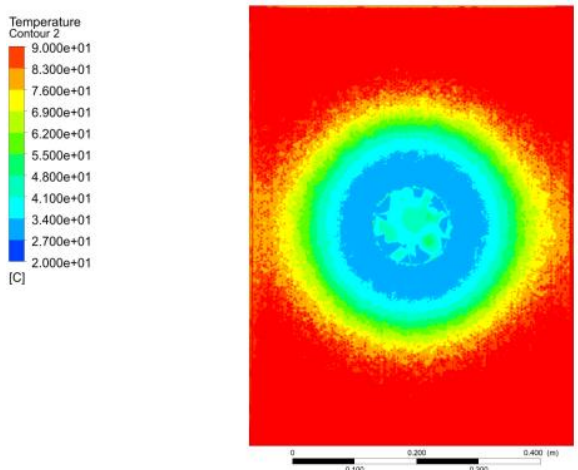

$\underset{202002}{\text { ANSYS }}$

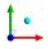

Şekil 11. Merkez hava çekişli güneş hava kollektöründe soğurucu yüzeyin sıcaklık değişimi $\left(1000 \mathrm{~W} / \mathrm{m}^{2} 1\right.$ şııım ve 0.015 $\mathrm{kg} / \mathrm{s}$ debi)
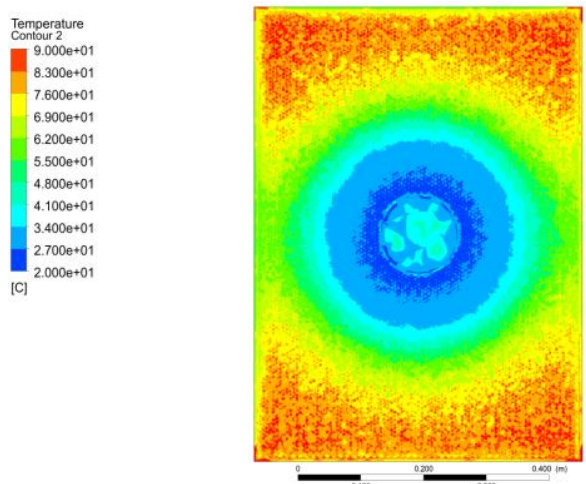

$\underset{2020 \mathrm{R} 2}{\text { ANSYS }}$

Şekil 12. Merkez hava çekişli güneş hava kollektöründe soğurucu yüzeyin sıcaklık değişimi $\left(600 \mathrm{~W} / \mathrm{m}^{2}\right.$ 1şınım ve 0.015 $\mathrm{kg} / \mathrm{s}$ debi)

Güneş hava kollektörünün hava çıkışının kollektör merkezinden olduğu durumda, kollektörden çıkan havanın en yüksek olduğu sıcaklığın $1000 \mathrm{~W} / \mathrm{m}^{2}$ 1şınım ve $0,01 \mathrm{~kg} / \mathrm{s}$ debide gerçekleştirilen analize ait olduğu görülmüştür (Şekil 13). En yüksek termal verimde yine tasarım 1 gibi $600 \mathrm{~W} / \mathrm{m}^{2} 1$ şınım ve $0,015 \mathrm{~kg} / \mathrm{s}$ debi için gerçekleştirilen analizde bulunmuştur (Şekil 14).

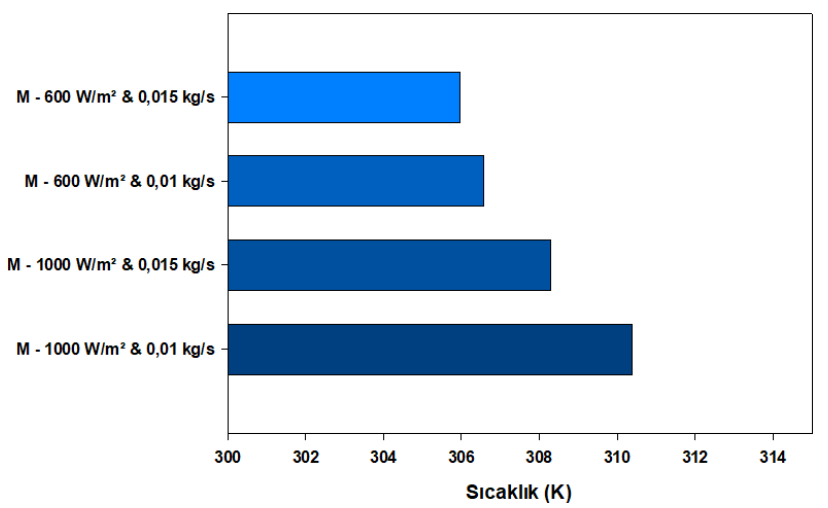

Şekil 13. Merkezi hava çekişli güneş hava kollektöründe çıkış sıcaklığı değişismi

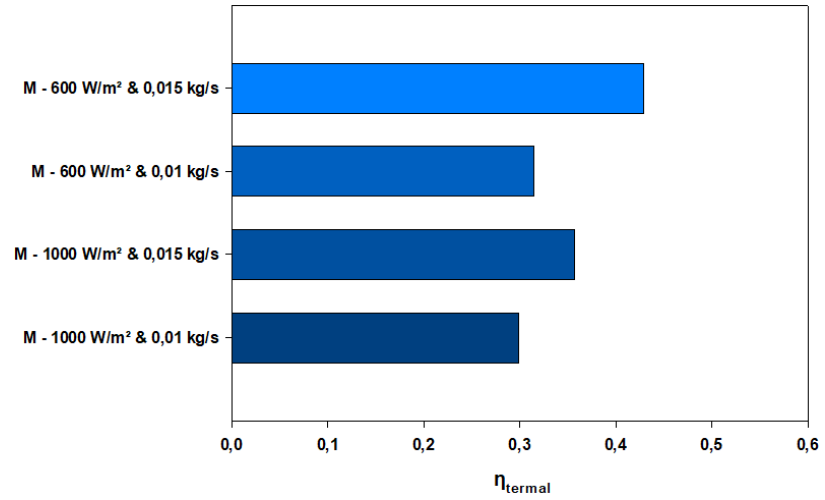

Şekil 14. Kenar hava çekişli güneş hava kollektöründe termal verimlilik değişimi

\section{Sonuç}

Bu çalışmada, bir güneş hava kollektörü tasarımının hava çıkış yerine göre HAD (Hesaplamalı Akışkanlar Dinamiği) analizleri gerçekleştirilmiştir. Güneş hava kollektörünün verimini artırmak için balpeteği geometrisine sahip bir alüminyum soğurucu plaka kullanılmıştır. Isı transferi ve hava akış özelliklerini incelemek için merkez ve kenar hava çekişli güneş hava kollektörü üzerine HAD analizleri yapılmış, farklı 1şınım ve kütle debileri altında sistemin optimum çalışma aralıkları belirlenerek merkez ve kenar hava çekişli kollektörlerin tasarım karşılaştırılması yapılmıştır.

Farklı ışınım ve hava debileri için analizleri gerçekleştirilen 2 farklı tasarıma sahip güneş hava kollektöründen elde edilen bulgular değerlendirildiğinde;

- En yüksek hava çıkış sıcaklığına, $1000 \mathrm{~W} / \mathrm{m}^{2} 1$ şınım ve $0,01 \mathrm{~kg} / \mathrm{s}$ debi için kenar kısımdan hava çekişli tasarım 1 'de, en düşük hava çıkış sıcaklığına, $600 \mathrm{~W} / \mathrm{m}^{2} 1$ şınım ve $0,015 \mathrm{~kg} / \mathrm{s}$ debi için merkez kısımdan hava çekişli tasarım 2'de ulaşılmıştır.

- En yüksek termal verimliliğe, $600 \mathrm{~W} / \mathrm{m}^{2} 1$ șınım ve $0,015 \mathrm{~kg} / \mathrm{s}$ debi için kenardan hava çekişli tasarım 1'de, en düşük termal verimliliğe $1000 \mathrm{~W} / \mathrm{m}^{2} 1$ şınım ve 0,01 $\mathrm{kg} / \mathrm{s}$ debi için merkezden hava çekişli tasarım 2'de ulaşılmıştır.

- Her iki tasarımda köşe bölgelerde hava akışının yetersiz olduğu ve bu nedenle hem analizde hem de tasarımda optimizasyon yapılabileceği görülmüştür.

İlerleyen çalışmalarda, bu çalışma kapsamında önerilen güneş hava kollektörünün $\mathrm{HAD}$ analizi, farklı alüminyum balpeteği hücre büyüklükleri ve soğurucu katman kalınlığı, daha geniş 1şınım ve debi aralıklarını da içerecek şekilde genişletilecektir. Analiz sonuçlarına göre alüminyum soğurucu katmana sahip güneş hava kollektör prototipleri üretilecektir. Üretilecek güneş hava kollektörlerinin deneysel çalışmaları karşılaştırmalı olarak yapılacaktır. Elde edilen deneysel sonuçlar simülasyon sonuçlarıyla karşılaştırılarak ayrıca model iyileştirmeleri de gerçekleştirilecektir.

\section{Teşekkür}

$\mathrm{Bu}$ çalışma Necmettin Erbakan Üniversitesi BAP Birimi tarafından 2113MER03003 No.lu proje ile desteklenmiştir. 
Ayrıca, bu makale YTB'nin 'Danışmanınla Tarihe Not Düş!' projesi kapsamında desteklenmiştir.

\section{Kaynakça}

[1] Parlamış, H., Özden, E., \& Büker, M. S. (2021). Experimental performance analysis of a parabolic trough solar air collector with helical-screw tape insert: A comparative study. Sustainable Energy Technologies and Assessments, 47, 101562.

[2] Buker, M. S., \& Riffat, S. B. (2015). Building integrated solar thermal collectors-A review. Renewable and Sustainable Energy Reviews, 51, 327-346.

[3] Kumar, R., \& Chand, P. (2018). Performance prediction of extended surface absorber solar air collector with twisted tape inserts. Solar Energy, 169, 40-48.

[4] Alkilinç, H., \& Büker, M. S. (2021, June). Performance Assessment of Partially Shaded PV Modules With Microcracks. In 2021 29th Signal Processing and Communications Applications Conference (SIU) (pp. 1-4). IEEE.

[5] Zhao, Y., Meng, T., Jing, C., Hu, J., \& Qian, S. (2020). Experimental and numerical investigation on thermal performance of PV-driven aluminium honeycomb solar air collector. Solar Energy, 204, 294-306.

[6] Hu, J., \& Zhang, G. (2019). Performance improvement of solar air collector based on airflow reorganization: A review. Applied Thermal Engineering, 155, 592-611.

[7] Kabeel, A. E., Khalil, A., Shalaby, S. M., \& Zayed, M. E. (2016). Investigation of the thermal performances of flat, finned, and v-corrugated plate solar air heaters. Journal of Solar Energy Engineering, 138(5), 051004

[8] Sudhakar, P., \& Cheralathan, M. (2019). Thermal performance enhancement of solar air collector using a novel Vgroove absorber plate with pin-fins for drying agricultural products: an experimental study. Journal of Thermal Analysis and Calorimetry, 1-12.

[9] Tuncer, A. D., Sözen, A., Khanlari, A., Amini, A., \& Şirin, C. (2020). Thermal performance analysis of a quadruple-pass solar air collector assisted pilot-scale greenhouse dryer. Solar Energy, 203, 304-316.

[10] Gao, W., Lin, W., Liu, T., \& Xia, C. (2007). Analytical and experimental studies on the thermal performance of crosscorrugated and flat-plate solar air heaters. Applied Energy, 84(4), 425-441.

[11] Priyam, A., \& Chand, P. (2018). Effect of wavelength and amplitude on the performance of wavy finned absorber solar air heater. Renewable energy, 119, 690-702.

[12] Zhao, Y., Meng, T., Jing, C., Hu, J., \& Qian, S. (2020). Experimental and numerical investigation on thermal performance of PV-driven aluminium honeycomb solar air collector. Solar Energy, 204, 294-306.

[13] Abuşka, M., Şevik, S., \& Kayapunar, A. (2019). Experimental analysis of solar air collector with PCMhoneycomb combination under the natural convection. Solar Energy Materials and Solar Cells, 195, 299-308.

[14] Zulkifle, I., Alwaeli, A. H., Ruslan, M. H., Ibarahim, Z., Othman, M. Y. H., \& Sopian, K. (2018). Numerical investigation of V-groove air-collector performance with changing cover in e-ISSN: 2148-2683
Bangi, Malaysia. Case studies in thermal engineering, 12, 587599.

[15] Fudholi, A., Zohri, M., Rukman, N. S. B., Nazri, N. S., Mustapha, M., Yen, C. H., ... \& Sopian, K. (2019). Exergy and sustainability index of photovoltaic thermal (PVT) air collector: A theoretical and experimental study. Renewable and Sustainable Energy Reviews, 100, 44-51.

[16] Kareem, M. W., Habib, K., Sopian, K., \& Irshad, K. (2016). Performance evaluation of a novel multi-pass solar air heating collector. Procedia engineering, 148, 638-645.

[17] Afshari, F., Zavaragh, H. G., Sahin, B., Grifoni, R. C., Corvaro, F., Marchetti, B., \& Polonara, F. (2018). On numerical methods; optimization of CFD solution to evaluate fluid flow around a sample object at low Re numbers. Mathematics and Computers in Simulation, 152, 51-68.

[18] Sözen, A., Kazancioğlu, F. Ş., Tuncer, A. D., Khanlari, A., Bilge, Y. C., \& Gungor, A. (2021). Thermal performance improvement of an indirect solar dryer with tube-type absorber packed with aluminum wool. Solar Energy, 217, 328-341.

[19] Ahsan, M. (2014). Numerical analysis of friction factor for a fully developed turbulent flow using $\mathrm{k}-\varepsilon$ turbulence model with enhanced wall treatment. Beni-Suef University journal of basic and applied sciences, 3(4), 269-277.

[20] Rajarajeswari, K., Alok, P., \& Sreekumar, A. (2018). Simulation and experimental investigation of fluid flow in porous and non-porous solar air heaters. Solar Energy, 171, 258270.

[21] Alic, E., Das, M., \& Akpinar, E. K. (2021). Design, manufacturing, numerical analysis and environmental effects of single-pass forced convection solar air collector. Journal of Cleaner Production, 311, 127518.

[22] Solar Air Collector, Solar Venti, SV3 Air - Up to $25 \mathrm{~m}^{2}-$ SolarVenti Ltd. (17.11.2021)

[23] Kumar, A., \& Layek, A. (2019). Energetic and exergetic performance evaluation of solar air heater with twisted rib roughness on absorber plate. Journal of Cleaner Production, 232, 617-628. 